\title{
Adjudication in Construction Contracts
}

\author{
A. Ranasinghe and J.C. Korale
}

\begin{abstract}
Adjudication is a form of alternate dispute resolution method used widely in the construction industry. This process is carried out by an independent person selected by the parties in a contract.

The Adjudicator has to carry out a fairly detailed study of the dispute referred to him and such work includes investigation, identification of the dispute, legal and contractual issues. The parties to the dispute are free to make their own presentations in the form of documentary and verbal evidence, photographs, reports etc. The duration of adjudication is limited to the number of days in the contract agreement they have entered into. The Adjudicator also might have to carry out site visits, meetings etc. to obtain further clarification with respect to the disputed matters.

It is also equally important that the principles of natural justice have to be followed by the Adjudicator. Generally, in adjudication, no legal representations are made by the parties and the decision is made by the Adjudicator mostly from the factual issues raised by the parties. The decision of the Adjudicator has to be implemented forthwith and the dissatisfied party is free to challenge the decision of the Adjudicator in another tribunal depending on the agreed terms.
\end{abstract}

Keywords: Adjudication, Arbitration, Conditions of Contract, FIDIC, ICTAD, Neutral, Bias, Representation.

\section{Introduction}

Adjudication is an alternate dispute resolution process wherein disputants refer a dispute to a neutral and impartial third party identified as Adjudicator, by mutual agreement, to decide on the matters in dispute and declare an award, i.e. decision, within a predetermined time frame or such extended time as agreed between the parties, on inquiry of disputed facts and law on an inquisitorial manner.

Most commercial disputes can be referred to adjudication.

In the case of construction disputes in Sri Lanka that are not resolved by negotiation, Engineer's decision or other means, may inevitably reach the stage of adjudication prior to arbitration or litigation as the case may be as provided in the contract.

Adjudication has become an extremely popular concept in construction dispute resolution. A dispute may be - 'adjudicated on/adjudicated upon/adjudicated between A \& B.' In so far as dispute resolution is concerned. Adjudication encompasses another form of alternative dispute resolution process.

\section{Conflicts, Disputes \& Alternate Dispute Resolution}

It is worthwhile to consider what is meant by 'Alternative Dispute Resolution' (ADR). ADR can be defined as those procedures or methodologies of resolving conflicts that are alternative to litigation and the like. ADR encompasses a myriad of conflict resolution approaches ranging from negotiation to arbitration which includes facilitation and mediation as well. [1] ADR is also defined as the dispute resolution process which encourages or facilitates the disputants to reach a solution to their disputes having appointed their own judges. Furthermore ADR also includes conciliation, mediation and 'mini-trials'.[2] ADR is growing into a variety of applications on business contracts including but not limited to civil engineering and employment.

Eng. A. Ranasinghe, BSc Eng (Hons), MEng, MTech, PGD, CEng, IEngPE, AIStructE, FIE (Sri Lanka), MIE (Aust), MICE, Attorney-at-Law

Presently working as a Consultant, Adjudicator and Arbitrator. Visiting Lecturer at University of Moratuwa, University of Peradeniya, ICLP Arbitration Centre.

J.C. Korale, BSc., MSc., FCMA, ACA,

Consultant in Contract Management and Administration, Chartered Accountant, Chartered Management Accountant, Visiting Lecturer on Conflict Management, Uva Wellassa University 
In the Sri Lankan context ADR is making its mark in the business of finance, construction, shipping and other trades other than employment disputes. In the field of construction invariably negotiations take place at almost every stage from the tender notice up to the last date of the defect liability period.

The most important forms of ADR are adjudication and arbitration. Both these dispute resolution methodologies mostly command their importance by way of contractual clauses embodied in the respective contracts even though there are exceptions to the rule.

The dictionary meaning of "adjudication" is 'pronouncing judgment or making an official decision about who is right in a disagreement between two groups or two organisations.'[ [3]. It is noteworthy to examine the word 'conflict' and how a conflict becomes a dispute with reference to Alternative Dispute Resolution. The dictionary meaning of conflict is, "A situation in which people, a group or countries are involved in a serious disagreement or argument." $\left.{ }^{4}\right]$ 'Conflict' is also defined by various authors in various manners and a few of such definitions are reproduced below:

- A process that begins when one party perceives that another party has negatively affected, or is about to negatively affects something that the first party cares about.[5]

- Conflict exists when two or more parties disagree about something. These parties are interdependent, meaning that the resolution of the conflict to mutual satisfaction cannot occur without some mutual effort. $\left.{ }^{6}\right]$

- A dispute is the result of an unsettled conflict where the arguing parties are unable to settle their differences or reach a compromise. It is an argument or a quarrel. The dispute exists because the potential differences have been realized and the parties have been unable to resolve them. [ ${ }^{7]}$

A civil engineering contract particularly one of any magnitude, which did not give rise to some dispute, is not to the discredit of either party to the contract. It is simply the nature of the beast. What is to their discredit is if they fail to resolve those disputes as quickly, economically and sensibly as possible. [ $\left.{ }^{[}\right]$

\section{Adjudication in Construction}

Adjudication initially existed only in a limited number of Conditions of Contracts. New Civil Engineering contracts as well as JCT (Joint Contracts Tribunal) contracts where the Conditions of Contract use the adjudication process for the very first time. Later, the 1999 Edition of FIDIC Conditions of Contract introduced adjudication although in earlier editions of FIDIC dispute resolution was restricted to arbitration. Arbitration has been there in most of the contract documents, at least for three decades although the Arbitration Act was enforced as late as the 1996 even in countries like the UK. [9]

The ICTAD Conditions of Contract introduced Adjudication in its SBD (Standard Bidding Document) versions. The idea of having Adjudication in the Conditions of Contract is that while the parties reserve their right to refer the matter to Arbitration, they also have the freedom of referring any dispute to Adjudication in order to obtain a quick solution while the contract is in progress. $\left[{ }^{10]}\right.$

There is a view in the construction industry that as the Engineer in a contract is appointed by the Employer he has to be obliged and looks after the interests of the Employer. By referring to the 1999 Edition of FIDIC Conditions of Contract, one could see that the Engineer is defined as a person appointed by the Employer to act as the Engineer for the purposes of the contract and named in the Appendix to Tender, or other person appointed from time to time by the Employer and notified to the Contractor. Although the Engineer should act impartially, there is a belief that the Engineer is not an independent person. As a result of this belief, most of the contracting parties have considered that it could be much advantageous to have an independent person to resolve probable disputes in the contract and as a result Adjudication has been introduced in most of the modern Conditions of Contract the world over.

Therefore, the spirit of resolving disputes by adjudication is, when two parties enter into a contract where they have contractual obligations and if they cannot agree on how the contract is to be interpreted, to refer the matter to an independent person. The Adjudicator, presumed to be an impartial person having knowledge about the contract and the subject 
matter, gives a quick working decision on the issues that have arisen in the contract. This will definitely enable the contract to continue without any interruption and the disagreeing party to the Adjudicator's decision could resort to arbitration or litigation at a future date.

\section{Statutory Adjudication and Contractual Adjudication}

Adjudication begins when there is a dispute in a construction contract depending on the applicable dispute resolution mechanism and/or the legislation of the country.

Construction disputes governed by legislation such as the Housing Grant Construction and Regeneration Act 1996 of U.K., or similar statute in a State providing for adjudication of disputes by compulsion, creates the provision for an ADR process called Statutory Adjudication.

In countries such as Sri Lanka where there is no statute governing adjudication, the adjudication process is provided for in the conditions of contract, giving rise to an ADR process called Contractual Adjudication.

In the Sri Lankan context there is no statute governing adjudication as stated above. Hence, at present in the Sri Lankan context one would not encounter statutory adjudications as well as complications arising out of both parties opting to adjudicate under different adjudications on the same matter giving rise to situations where there could be two adjudications on the same matter simultaneously. Most construction contracts include provision for any claim or any other issue or problem to be notified to the Engineer and the other party when the problem first arises. This would encourage the parties to negotiate and finally settle in accordance with certain stated procedures upon agreeing to such procedure.

The adjudication process can be viewed as consisting of 6 components:

1. Before the Adjudication

2. Notice of Adjudication

3. Selection and appointment of the Adjudicator

4. Referral of the dispute to the Adjudicator

5. Conduct of the Adjudication

6. The Adjudicator's decision

\section{Before the Adjudication}

A prerequisite for adjudication is a "dispute". Some contracts define the word 'dispute' and prescribe the procedure to be followed whereas others do not define the dispute procedure and the first indication that a dispute has arisen could be when one party to the contract issues a notice of intention to refer the dispute to adjudication.

John Timpson \& Brian Totterdill [1999] state in their famous book Adjudication for Architects and Engineers as follows:

"The fact that an issue can be declared to be a dispute and referred to Adjudication does not necessarily mean that adjudication is the best way forward. The person who is considering the referral must be satisfied that immediate adjudication is the best course of action and is in his or her own best interests. This requires consideration of the sequence of questions which are as follows:

- What is the issue which we are trying to resolve?

- Have I made my views clear to the other side? Do they realise that the initial problem has become a dispute and I intend to involve an independent dispute resolver?

- Would further investigation or tests help to clarify the cause of the problem and resolve the dispute? If so, should the investigation or tests to be carried out before I refer the matter to adjudication?

- Will an impartial decision, within a limited time period, be helpful to the project as a whole?

- Is adjudication appropriate for this particular problem, or is there a better way forward? Should I try further negotiation, mediation or conciliation?

- Would it be better to refer the problem direct to Arbitration? Is immediate Arbitration permitted by the Contract?

- Is there any procedure which must be followed before the problem can be referred to Adjudication?"

Adjudication should not be resorted to without proper consideration of its consequences. Adjudication is, in principle, a procedure which leads to an impartial decision within the given time period. The decision must be implemented but implementation may be later reversed by arbitration or litigation. Some issues and 
disputes in construction may not be best resolved by adjudication.

The following are some of the examples which are not suitable for adjudication, though not exhaustive:

- Disputes which comprise several issues. These may need to be considered as separate disputes with separate adjudications or as requiring a series of decisions over an extended period.

- Disputes involving complex legal issues.

- Disputes which require a decision, the consequences of which cannot be reversed, such as a matter of termination, alleged corruption or allegations against a professional person.

- Matters such as design or quality, which affect the form of the completed project and for which the Contract states that one of the Parties is responsible for the issue of decisions or instructions. Disputes concerning the liability for additional costs as a consequence of such a decision or instruction are more likely to be suitable.

- Matters on which the decision is within the province of some other person or authority, such as VAT, taxation issues, health and safety, or any allegation with criminal implications must be referred to the proper authority.

\section{Notice of Adjudication}

For an adjudication to commence, the person who decides to refer a dispute must inform the other party of his intention. This is termed 'Notice of Adjudication' from 'Referring Party' to the 'Other Party' who is also known as the 'Responding Party' or 'Receiving Party'. The notice should always be in writing and shall comply with any procedure stipulated in the contract if any. Notice should include sufficient information to satisfy this purpose, mainly -

- Particulars of dispute to be referred to adjudication.

- Appraise nominating body/potential Adjudicator basic information.

At this point the Adjudicator will be selected, if not already named in the contract, and the matter will be adjudicated in terms of notice of adjudication and the contract.
It is pertinent to note that neither party will be permitted to introduce additional issues at the hearing. If either party wishes to have some other matter, additional claim or a counter claim for consideration, it should be referred by a separate notice of adjudication unless both parties and the Adjudicator agree to extend the scope of the pending adjudication. This is also a situation where party autonomy governs. Simultaneously, if any party wishes to raise any procedural objection it must be raised immediately, otherwise it is considered that the right to object had been waived. The Adjudicator has the jurisdiction to take up any objection including that of the appointment of the adjudicator. Some contracts encourage the appointment of an adjudicator as early as the tender stage. If the Adjudicator had been appointed at the beginning, he is available to resolve any dispute since the inception. In some Contracts the Employer names the Adjudicator in the Tender Document itself. However if the Contractor is not comfortable with such an appointment he could object to this unilateral appointment.

\section{Selection and Appointment of the Adjudicator}

The Adjudicator must be selected and appointed in order for the process to commence. Irrespective of whether the Adjudicator is appointed at the start of the project or after the dispute has arisen it is of primary importance to appoint a suitable person. It is extremely important that the person appointed as an Adjudicator must be knowledgeable and have experience in the type of construction project that he is going to adjudicate. He should also be able to understand the issue that could arise in a contract of the aforesaid nature. It is also of primary importance that the Adjudicator has basic training as an Adjudicator, knowledge in Conditions of Contract together with the confidence in making a decision. Apart from this the Adjudicator should not have any interests in the Project. The important factors that have to be looked into when selecting an Adjudicator are summarised below:

- It is necessary to check that the appointed Adjudicator is still available when the dispute actually arises. There may have been changes in his health or circumstances since the appointment. Adjudication requires intensive activity 
during a short period and he may have other commitments which would prevent him from allocating sufficient time to the adjudication.

- A possible conflict of interest may have arisen which was not known when he was appointed.

- A particular dispute may require specialised knowledge which is not possessed by an Adjudicator.

- If practicing Adjudicators are named in a large number of contracts, or appointed but not used, it becomes impossible for them to plan their availability for other appointments.

Procedure for the actual appointment can vary and may include applying to an appointing or nominating body made in the contract, chosen by agreement or chosen unilaterally by the referring party. The procedure should be studied by both parties and the Adjudicator in his own interest. There are many advantages in appointing an Adjudicator at the inception of the Project as it gives sufficient time for the parties and the Adjudicator to discuss terms and fees.

\section{Referral of the Dispute to the Adjudicator}

The mechanics of referral and response vary in different adjudication procedures but are generally based on the following:

- The Adjudicator has been appointed and has a copy of the Notice of Adjudication.

- The referring Party sends the Adjudicator his 'Statement of Case' with a copy to the other Party.

- The responding Party sends the Adjudicator his response, with a copy to the referring Party.

The referring party will usually take advantage of the opportunity to provide detailed explanation of the case usually known as "Statement of Claim". A well argued presentation, legal or contractual arguments backed by authoritative references will have a persuasive effect on the Adjudicator. The referring party also has an advantage of timing the adjudication process.

It is a misnomer to believe that the greater the number of pages the more persuasive is the Statement of Claim.
It must be borne in mind that the Statement of Claim should be clear, concise and logical. As the adjudication will be taking place within a restricted time frame, clarity of the communication is essential. The Statement of Claim should not be restricted rigidly to one sided argument. There could have been an exchange of correspondence, discussions, request for further information and investigations and such complete communication should be presented to the Adjudicator. It is to the best interest of the referring party that the Adjudicator achieves a clear understanding of the dispute and the logical sequences of events within the least possible time during the adjudication period which invariably is stipulated. In a major dispute, the Statement of Claim may include -

- A brief summary of the dispute and the problem which led to the dispute.

- Evidence in the form of documents, photographs, witness statements and/or expert opinion to establish the factual basis of the claim.

- Legal and contractual arguments on which the claim is based with the authorities, when available.

John Timpson \& Brian Totterdill [1999] state in their famous book Adjudication for Architects and Engineers as follows:

"If the referring Party is anxious to prove its case, it will, while preparing its Statement of Claim:

- Make sure of its legal and contractual position before embarking on the process

- Avoid ambiguity so as not to leave any room for doubt

- Check and double check all factual matters

- Avoid exaggeration and speculative allegations

- Look at every point from the opposite point of view and satisfy that there are no weaknesses in the arguments or evidence.

- Take specialist advice wherever necessary.

- Make sure that the evidence convincingly supports any allegations or refutations.

- Have regard to the fact that it is a difficult task to set down unambiguously and exactly what happened and how and why the case is justified.[11] 


\section{Conduct of Adjudication}

It is customary that the conduct of adjudication is subject to a time frame. In a case where adjudication is required to be concluded within 28 days a typical programme is appended below:

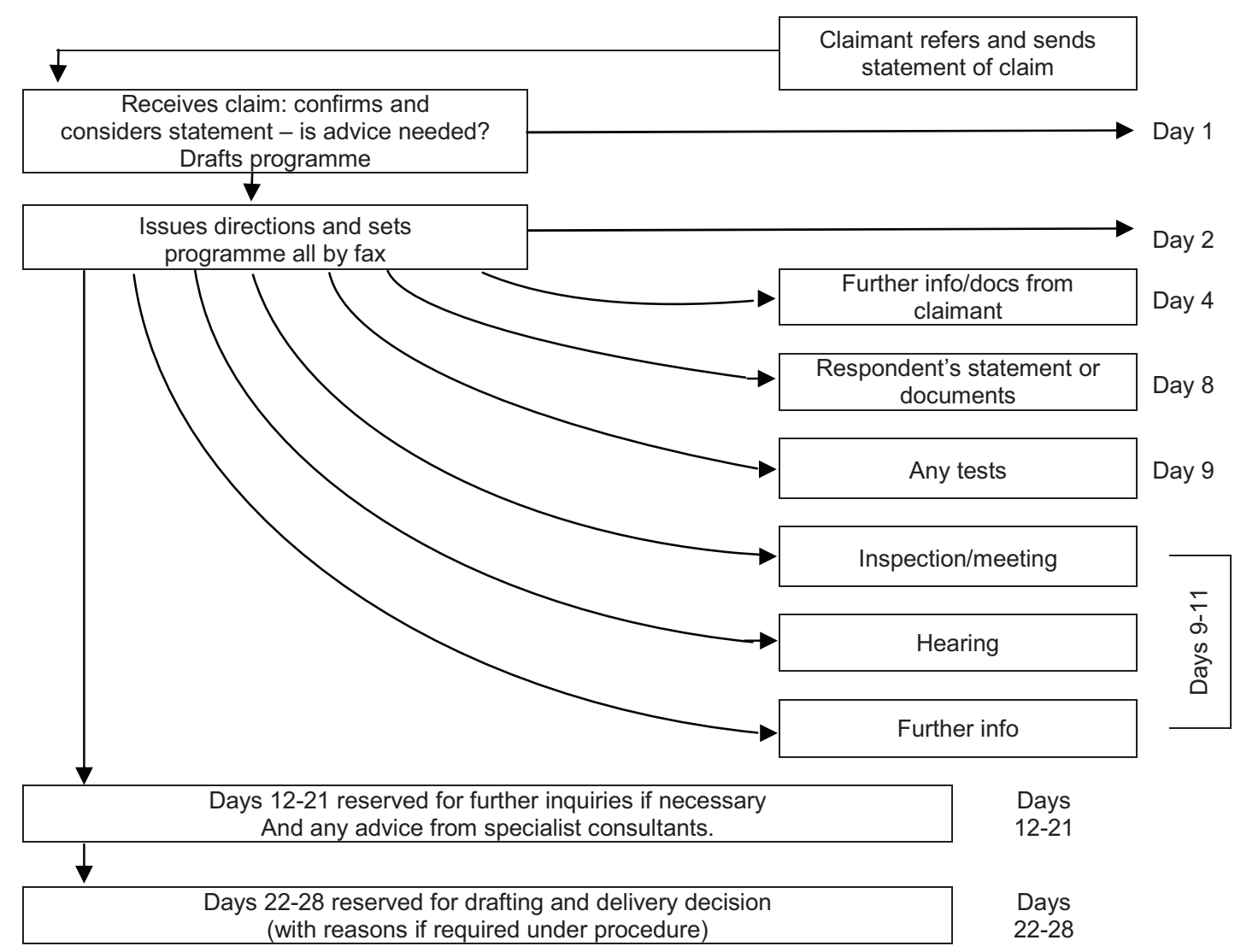

Figure 1 - Adjudication Document Flow \& Typical Programme

Immediately after, the Adjudicator would study the Statement of Claim and prepare the provisional timetable for the Adjudication. A typical programme is shown above in Figure 1.

The timetable will show how he proposes to complete his work within the time period which is permitted by the contract procedure, based on his assumptions as to the action which will be necessary. It will also take into account any requests from the parties, together with the requirements of his own diary. If the contract procedure does not allow specifically for a response from the responding party then the Adjudicator may include a suitable provision.

The Adjudicator will revise the initial timetable as the adjudication proceeds and further information becomes available. The timetable will include a period for the Adjudicator to assess the information which he has received, to Arrive at his decision and to prepare his written decision.

\section{The Adjudicator's Decision}

The aim of adjudication is for the parties to receive an impartial decision on their dispute within the stipulated time. The written decision which is sometimes known as the Determination of the Adjudicator is the product of the Adjudicator's work which the parties receive in exchange for a fee.

The Adjudicator's decision is not an arbitral award and will normally be shorter than an award on a comparable dispute. There is no standard format or generally agreed list of contents for a Decision. The contracts are written contracts as required by the law so that the Adjudicator's decision will be a written decision.

There are salient features in the process such as the response of the time period of Adjudication, existence of Natural justice, adjudication meetings, site visits, ascertainment of facts and 
Law pertaining to the adjudication as well as obtaining of specialists advice by the Adjudicator.

\section{The Response}

When the referring party has sent a Statement of Claim to the adjudicator, the other party will want to respond. The response may need to be submitted within the stipulated time period either as per the contract or on the direction of the Adjudicator. Once the Adjudicator receives the response he can assess both parties' points of view. When an issue has come to the point of notice of adjudication, the particular dispute would have been discussed, negotiated over a considerable period of time and investigated over the same period and a certain point of response might have been developed. The responding party will know all about the initial problem, have decided to reject the claim and during this process appropriate investigations would have been conducted and the basis of the rejection is readily available with them. If the referring party has created an ambush situation then the responding party will be faced with a difficult or even impossible task. The Response to a detailed Statement of Claim may include:

- A brief summary of the dispute and the problem which led to the dispute, explaining the counter point of view and reasons for rejecting the claim

- Legal and contractual counter arguments with authorities

- Evidence in the form of documents, photographs, witnesses and/ or expert opinion to support any counter arguments and allegations

In such a situation the rules that have to be followed by the Respondent are to:

- Read carefully any claim statement

- Deal with the matter thoroughly

- Ask for clarification of any ambiguity

- Insist that any allegation is supported by evidence, including details of when and where any alleged events are said to have taken place

- Make sure that it has dealt with every point made or implied
- Point out every factual error and collate evidence which will assist with the Adjudicator's understanding of the case

- Consider any contractual or legal point and make sure that everything which can be rebutted is rebutted

- Admit those things which are correct but make it clear exactly which points are contested

- Make sure the record is complete

- If the Claimant has given only half the story, admit that which is true but explain fully the missing part of the picture which may put a different complexion on the whole affair.[12]

\section{The Adjudication time period}

The purpose of adjudication is a fast decision. The time period which is available for the adjudication process depends on a contract and is always restricted and cannot be unilaterally extended by the Adjudicator. The Adjudicator is required to assess all established relevant facts and law, reach a good decision on different matters. This will depend on the details of dispute and the cooperation of the parties. In terms of the FIDIC Conditions of Contract the Adjudicator has been given 84 days to resolve a dispute and to give a decision whereas in the ICTAD SBD (Standard Bidding Document) the duration has been shortened to 28 days or such other period agreed by the parties. The whole idea of reducing the number of days is to facilitate a quick decision during the progress of construction. However, this does not, under any circumstances mean that the Adjudicator has to consider only a portion of the facts that he could grasp and give a hasty decision. It should be emphasised that the Adjudicator has a greater responsibility to give a proper decision by careful consideration of all the facts available, since the decision of the Adjudicator has to be given effect forthwith by the parties. This has been stated in Clause 20.4 of the FIDIC Condition of Contract. Paragraph 4 of Clause 20.4 states that "the decision shall be binding on both parties who shall promptly give effect to it unless and until is shall be revised in an amicable settlement or an arbitral award......". Similarly, Clause 19.3 Procedure for Adjudication in ICTAD SBD, Major Contracts (ICTAD/SBD/02) states that, "The decision of the Adjudicator shall be deemed final and binding on the 
parties if neither party refers the dispute to arbitration...."

It is pertinent to note that the time given to the Adjudicator is very limited and therefore it is the responsibility of the parties not to refer disputes of a very complex nature in one's reference. Parties have to be very careful not to allow a dispute to accumulate into a very complex nature as the Adjudicator will not be able to decide within a very limited time.

\section{Adjudicator Meetings, Site Visits, Ascertainment of Fact and Law and Specialists Advice}

The Adjudicator may decide to hold a meeting with the parties and give an opportunity to explain their own case in person and submit oral evidence. The meeting will facilitate:

- To resolve any queries on jurisdiction, the interpretation of the Notice of Adjudication or other preliminary matters.

- To clarify any points in the Statement of Claim or response

- To visit the site and to inspect any particular part of the Works

- To arrange for tests or opening up of the work and inspect the results

- To hear oral evidence

- To discuss queries and resolve any problems which can be sorted out quickly by discussion than by correspondence.

Site visits are essential features in most dispute adjudications because any dispute will involve quality of workmanship or something happening in the construction site and hence the Adjudicator may observe the problem himself. The site may be under the control of one party yet the Adjudicator may obtain necessary permission from the other party as well thus avoiding the situation in which one party takes advantage of the site visit by trying to influence the Adjudicator with new arguments and facts that are alien to the other party for which the opposing party can be present if so desired. The Adjudicator is under no obligation to ascertain all the facts and the law and it would not be possible for him to do so within the restricted time. It may not be within the permissible time for detailed forensic investigations in to the problem, for example, to take samples and conduct tests at times may require more than 28 days. However, the Adjudicator can make his own initiative to make inquires, tests and seek expert opinion if he considers those will help him reach a good decision.

A natural consequence of power to take initiation in ascertaining facts and the law extend the power to consult or obtain specialist advice. The type of specialist, technical or legal, will depend on the subject of the dispute and the expertise of the Adjudicator. The expenses of these site visits, investigations, expert advice and opinions are to be borne by the parties.

\section{Adjudication and Natural Justice}

Adjudication is a process whereby party autonomy is recognized and is not an end in itself. In a sense Adjudicator's the decision shall be binding until the dispute is finally determined by litigation, arbitration or settlement.

The word 'nature' literally means the innate tendency or quality of things or objects and the word 'just' means upright, fair or proper. The expression 'natural justice' would therefore mean the innate quality of being fair.

Natural justice, which is another name for common sense justice, is ' the natural sense of what is right and wrong' and is the name of those principles which constitute the minimum requirement of justice and without adherence to which, justice would be a travesty. The purpose of following the principles of natural justice is prevention of miscarriage of justice and hence the observance thereof is the pragmatic requirement of fair play in action. In the famous case of Bangladesh Steamer Agent's Association $v$ Bangladesh Hon. Judge Narman J said " ... First, I think that the person accused should know the nature of the accusation made; secondly, that he should be given an opportunity to state his case; and thereby, of course, that the tribunal should act in good faith. I do not think that there really is anything more" $\left.{ }^{13}\right]$.

The adjudication procedure provides parties the notice of adjudication meetings, copies of statement of case, copies of response, times of site visits made known to parties, opportunity of forwarding their own case, opportunity of 
being heard, being present and be represented, all of which are ingredients of natural justice entailed in the process as the parties cooperate for a decision within a very short period of time. The Adjudicator acts impartially, independently and free of all bias. This is another form of Natural Justice so that he could uphold justice on the matter in dispute. In a sense the adjudication process, when conducted properly, provides natural justice for the disputants.

\section{Conclusion}

The Adjudicator is in charge of the adjudication and has a contract with the parties under which he has an obligation to reach a decision on the dispute within a fixed time frame. In order to achieve the desired result, parties should endeavour to provide the Adjudicator all necessary information, available reports, tests of investigation, assistance and cooperation. It is a mandatory requirement that all relevant documents be copied to both sides, oral information to be confirmed with documentary evidence. The Adjudicator should also work within the terms of reference, rules and the procedure under which his appointment has been made. If a party considers a particular decision is unreasonable or outside the authority of the Adjudicator, he could make his formal objection and the Adjudicator shall deal with the objection in a fair and reasonable manner. If either party fails to comply with the direction of the Adjudicator, the Adjudicator may continue in the best way possible and any such failure will be detrimental to the party who fails to comply. If an Adjudicator receives or discovers information after the stipulated closing date it is within his jurisdiction to use such information invariably with an agreed extension. Once the Adjudicator has reached and delivered his decision he has completed his task. If either party is not satisfied with the decision such party may proceed in terms of the law to arbitration or litigation, thus once again enjoying another form of Natural Justice i.e. the right of appealing.

The adjudication process is a new process which has been introduced to the construction industry. When comparing with the cost of arbitration, the cost of adjudication is very much less. It also should be emphasised that a speedier decision could be obtained by parties referring their disputes to adjudication. Generally in adjudication no legal representation is made by either party. Therefore there is very little legal objection taken by the parties. Mostly it would be decided by the facts presented by the parties. The author also believes that this proposal has made a revolutionary change in resolving construction disputes and the professionals who are involved in the construction industry have to be trained sufficiently to handle adjudication so that all parties concerned could save a substantial time and money in resolving construction disputes. The co-operation of all parties to the contract is a must to ensure a successful future for construction adjudication.

\section{References}

1. Marick, F., Masters et al, Complete Guide to Conflict Resolution, 2nd Edition, (Sweet \& Maxell), 2002, Page 10

2. John Timpson and Brian Totterdill, Adjudication for Architects and Engineers, Thomas Telford, 1999, Page 12, 168, 252

3. Hornby AS etel, Oxford Advance Dictionary, Oxford University Press, $7^{\text {th }}$ Edition, page 319

4. ibid

5. Stephen P. Robbins, Organizational Behaviour, Eleventh Edition, Prenhall.Com/robinbinsd), 2002, Page 96

6. Ibid (1)

7. Weddikkara, Chitra, The Impact of Professional Culture on Dispute Resolution in The Building Industries of Australia and Sri Lanka, Standen, 1987, Page 158.

8. Geoffrey Hawker, John, Uff, Charles Timms, Arbitration Practice, $2^{\text {nd }}$ Edition, Thomas Telford, 1986, Page 128.

9. http://www.fidic.org

10. ICTAD, Standard Bidding Document Procurement of Works, First Edition, ICTAD, 2002, Page 42.

11. Ibid (2)

12. $\operatorname{Ibid}(2)$

13. Tapash Gan Choudhury, Penumbra of Natural Justice, Second Edition, Eastern Law House, 2001, Page 1,5,9, 265. 
